\title{
The Effect of Temperature and Moisture Variation on the Heat Transfer Through Building Envelope
}

\author{
Maatouk Khoukhi, Ahmed Hassan, Shaimaa Abdelbaqi \\ Architectural Engineering Department, College of Engineering, United Arab Emirates University \\ PO Box 15551, Al Ain, UAE \\ mkhoukhi@uaeu.ac.ae; Ahmed.Hassan@uaeu.ac.ae; 200734406@uaeu.ac.ae
}

\begin{abstract}
This paper investigates the impact of the change of thermal conductivity of the insulation layer embedded in a typical residential building on the cooling effect. The simulation has been performed using the polystyrene (EPS), in extremely hot conditions of Al Ain (UAE) at different level of densities denoted as low density LD (12 kg/m3), high density HD (20 kg/m3), ultra-high density UHD (30 kg/m3) and super-high density SHD (35 kg/m3), and three moisture content levels $(10 \%, 20 \%$, and $30 \%)$ compared to dry insulation material for LD. The change of the thermal conductivity of the EPS material at different operating temperatures and moisture content has been investigated. The thermal wall resistance was evaluated by applying a conjugate heat transfer model based on enthalpy-based formulation. The thermal performance of the building incorporating polystyrene with variable thermal conductivity ( $\lambda$-value) was compared to a constant thermal conductivity by quantifying the additional cooling demand and capacity due to the $\lambda$-relationship with time using the e-quest as a building energy analysis tool. The results show that, when the $\lambda$-value is modelled as a function of operating temperature, its effect on the temperature profile during daytime is significant compared with that obtained when a constant $\lambda$-value for the polystyrene (EPS) insulation is adopted, however, this trend is reversed at night time. A similar trend in the evolution of temperatures across the wall section was observed when EPS material was tested with different densities and moisture contents. The monthly energy consumption for cooling required by the building is found to be higher in case of variable thermal conductivity for LD sample. The yearly average change in space cooling demand and cooling capacity employing polystyrene with constant and variable thermal conductivity increases with the increase of the moisture content. Indeed, the highest change in cooling demand and capacity are $6.5 \%$ and $8.8 \%$ with $30 \%$ moisture content.
\end{abstract}

Keywords: Temperature profile, Building insulation materials, Operating temperature, Moisture content, Space cooling, AC capacity.

\section{Introduction}

The buildings sector is responsible for $36 \%$ of global final energy consumption. Energy demand from buildings construction continues to rise, driven by improved access to energy in developing countries, greater ownership and use of energy-consuming devices, and rapid growth in global buildings floor area, at nearly 3\% per year. Without action, energy demand in the buildings sector could increase $30 \%$ by 2060 [1].

Energy consumption is continuously increasing in all sectors around the world. In the U.S., $40 \%$ of the total energy demand arises from buildings [2]. Under harsh weather, where industrial activities are not extensive, the building sector contributes around $70 \%$ to the total energy requirements, mainly due to the AC system use [3].

The building envelope is a physical barrier between the internal and external environments [4]. This barrier should provide an effective boundary for heat flow across the building envelope, which can be achieved by appropriate selection of insulation materials. Thermal insulation can be provided by organic or inorganic material, manufactured to reduce heat propagation by a combined heat transfer (i.e., conduction, convection, and radiation) [5].

The overall heat transfer coefficient (U-value) of the envelope is generally considered as a constant in pertinent calculations. This is however not true, as the U-value of the building envelope, a wall for instance, is a function of different layers particularly the insulation material which is a function of several parameters [3].

Actually, several researches [6,7] reported that the $\lambda$-value of the insulation material is a function of operating temperature and the moisture content in addition to the density of the material itself. Aldrich and Bond investigated the effects of temperature on the thermal performance of rigid cellular foam [8]. Their results show a significant change in the $\lambda$-value with temperature changes. Khoukhi and Tahat also investigated variations in the $\lambda$-values as a function of density, operating temperature, and humidity content of EPS insulation material, as well as the effects of these changes on the cooling load required by buildings $[9,10]$.

Several authors also investigated the impact of moisture content on the thermal conductivity of insulation materials. In these studies, thermal performance of polyurethane insulation [11], fiberglass [12] and mineral wool [13] expended 
for cooling and heating pipes exposed to the underground water attacks was investigated. The reported results indicate that thermal conductivity was $35-50 \%$ higher than the value obtained when the differences in temperature were larger. Similarly, Liu et al. reported that the accumulation of moisture and its transfer through exterior walls have a significant impact on the cooling and heating transmission [14].

Given the observations, the main objective of the present study was to investigate the effects of temperature and moisture content variations on the heat transfer through the wall assembly. The heat transfer variations were quantitatively assessed for EPS insulation material at different densities and various operating temperatures and moisture contents. The required space cooling and the yearly average change in space cooling demand and cooling capacity have been calculated for both constant and variable thermal conductivity. The difference in space cooling demand and capacity for the whole year at different moisture content for LD insulation material has been assessed accordingly.

\section{Numerical Model}

\subsection{Heat Transfer Analysis}

To simulate the thermal impact of applying constant and variable thermal conductivity of polystyrene insulation, a two-dimensional finite volume heat transfer model of the building wall was developed. $1-\mathrm{m}^{2}$ wall section, consist of 4 layers of concrete stucco, concrete block, insulation layer and interior gypsum, was modelled and solved in ANSYS platform (Version 18, Computer software company, Cecil Township, PA, USA, 2018), adopting Al Ain climatic conditions, characterized by the hot weather in July. The geometrical model was uniformly meshed using symmetric square cells with size of $0.5 \mathrm{~mm}$ as shown in Fig 1. Normalizing the solution residuals have been used as a criteria of solution convergence with the accuracy value of 1-E5. The transient temperature distribution at each node is determined iteratively by the solver. The solution is updated at 1-minute intervals, after completing 20 iterations, for a total run time of 24 hours

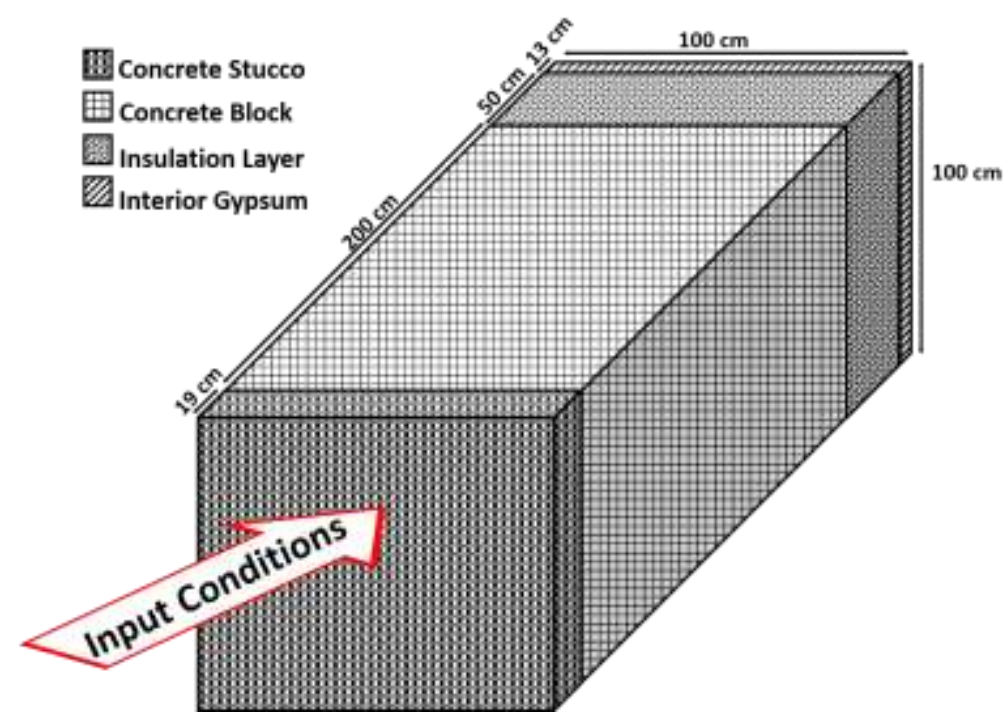

Fig. 1: The schematics diagram of the building wall cross-section, comprising of concrete stucco, concrete block, insulation layer, and interior gypsum.

The thermal boundary conditions were applied considering the exterior surface of the concrete stucco as the input heat flux boundary, including incident irradiance (q) with a convective-radiative mixed-mode heat loss.

The two-dimensional differential equation given below governs the transient heat transfer [15]:

$$
\rho c \frac{\partial T}{\partial t}-\left[\frac{\partial}{\partial x_{i}}\left(\lambda_{i j} \frac{\partial T}{\partial x_{j}}\right)\right]+Z_{c}+Z_{r}=0
$$


where $\boldsymbol{\rho}$ denotes density, $\boldsymbol{c}$ is heat capacity, $\boldsymbol{\lambda}$ is thermal conductivity of the material, $\boldsymbol{T}$ represents temperature, $\boldsymbol{t}$ is time, $\boldsymbol{x}_{\boldsymbol{i}}$ and $\boldsymbol{x}_{\boldsymbol{j}}$ denote unit vectors, $\boldsymbol{Z}_{\boldsymbol{c}}$ and $\boldsymbol{Z}_{\boldsymbol{r}}$ are conductive and radiative heat losses.

The convection heat loss is computed from Equation (2) as:

$$
Z_{c}=h_{\text {con }} \times A\left(T_{\text {Sur }}-T_{a m b}\right)
$$

The radiative heat loss is calculated from Stefan-Boltzmann law:

$$
Z_{r}=\sigma \varepsilon\left(\mathrm{T}_{\mathrm{Sur}^{4}}{ }^{-} \mathrm{T}_{\infty}{ }^{4}\right)
$$

where $\sigma$ is the Stephan-Boltzmann constant, $\varepsilon=0.97$ is the external emissivity, TSur is the surface temperature and $\mathrm{T} \infty$ is the infinity temperature.

The density, the velocity vector, and the specific heat capacity for the materials (denoted by $\rho, u j, c p$, respectively) are assumed to be independent of temperature, while the thermal conductivity $(\lambda)$ of the insulation material is treated as a function of temperature, and is defined by Eq. (4) [15]:

$$
\lambda(T)=C_{1}+C_{2} T+C_{2} T^{3} \cdots
$$

where $\lambda$ is thermal conductivity of the material, $C i$ are constant values pertinent to this work as shown in Table 1 and $T$

\begin{tabular}{|c|c|c|c|c|}
\hline \multirow{2}{*}{ Material } & Density & \multicolumn{3}{|r|}{ Thermal conductivity } \\
\hline & $\left(\mathrm{kg} / \mathrm{m}^{3}\right)$ & \multicolumn{3}{|r|}{$(\mathrm{W} / \mathrm{mK})$} \\
\hline Concrete stucco & 2000 & \multicolumn{3}{|r|}{1.2} \\
\hline Concrete block & 664 & \multicolumn{3}{|r|}{0.14} \\
\hline Interior gypsum & 625 & \multicolumn{3}{|r|}{0.16} \\
\hline \multirow{7}{*}{ Polystyrene } & \multirow{4}{*}{12} & \multirow{4}{*}{$\begin{array}{c}\text { Moisture } \\
\text { content } \\
(\%)\end{array}$} & $0 \%$ & $K(t)=9 \times 10^{-5}(T)+0.0372$ \\
\hline & & & $10 \%$ & $K(t)=9 \times 10^{-5}(T)+0.0386$ \\
\hline & & & $20 \%$ & $\mathrm{~K}(\mathrm{t})=9 \times 10^{-5}(\mathrm{~T})+0.0403$ \\
\hline & & & $30 \%$ & $\mathrm{~K}(\mathrm{t})=8 \times 10^{-5}(\mathrm{~T})+0.0426$ \\
\hline & 20 & \multicolumn{3}{|c|}{$\mathrm{K}_{\mathrm{HD}}(\mathrm{t})=6 \times 10^{-5}(\mathrm{~T})+0.0357$} \\
\hline & 30 & \multicolumn{3}{|c|}{$\mathrm{K}_{\mathrm{UHD}}(\mathrm{t})=5 \times 10^{-5}(\mathrm{~T})+0.0347$} \\
\hline & 35 & \multicolumn{3}{|c|}{$\mathrm{K}_{\mathrm{SHD}}(\mathrm{t})=6 \times 10^{-5}(\mathrm{~T})+0.033$} \\
\hline
\end{tabular}
denotes temperature.

Table 1: Thermo-physical properties of materials. [3]

\subsection{Building Energy Simulations}

The cooling energy demand of a typical one-story building (of $20 \mathrm{~m} \times 20 \mathrm{~m} \times 3 \mathrm{~m}$ dimensions) located in Al Ain (UAE), with a commonly used wall construction assembly comprising of $200 \mathrm{~mm}$ thick concrete block layer, a $50 \mathrm{~mm}$ insulation layer, a $13 \mathrm{~mm}$ thick interior gypsum board, and a $19 \mathrm{~mm}$ concrete stucco at the exterior surface was numerically simulated using e-quest program as a building energy analysis tool. The numerical model enables the analysis of multi-zone buildings including HVAC systems, internal loads from people, equipment and lighting, applying the hot weather condition of $\mathrm{Al}$ Ain UAE. The set temperature is $25^{\circ} \mathrm{C}$.

$\mathrm{Al}$ Ain is characterized by a very hot climate from May to October and the daytime and night-time average ambient temperatures for a typical day of the peak summer is $\sim 42{ }^{\circ} \mathrm{C}$ and $\sim 35{ }^{\circ} \mathrm{C}$, respectively. However, the weather remains hot for the whole year, with average daytime temperatures being above $27^{\circ} \mathrm{C}$, the upper range of thermal comfort. 


\section{Results and Discussion}

The aim of the simulation is to assess the heat transfer through the wall sections considering the variation of the value of the EPS insulation at different operating temperatures and moisture content. The results are then compared the base case with constant $\lambda$-value. The surface temperature was monitored before and after the insulation layer.

\subsection{Temperature Distribution}

The temperature profiles at the concrete-insulation and insulation-gypsum layers are shown in Fig.2. It can be noted that during the daytime, using variable $\lambda$-value results in a higher temperature rise on the surfaces compared to the reference case based on constant thermal conductivity of the insulation material. The change in temperature $(\Delta \mathrm{T})$ between applying variable and constant thermal conductivity is gradually increasing as the ambient temperature and solar radiation increase due to the increase of heat transfer in case of variable thermal conductivity. However, the trend is reversed at night-time, whereby employing variable $\lambda$ produces lower surface temperatures.

Across the wall section, at the location before the insulation layer (concrete- insulation), the temperature obtained when using a constant $\lambda$ and variable $\lambda$ are almost the same. However, in the subsequent wall layers, the difference is noticed. As the heat is transferred to the interior layers, $\Delta \mathrm{T}$ increases, reaching maximum on the surfaces located after the insulation layer toward the inner surface (insulation- gypsum).

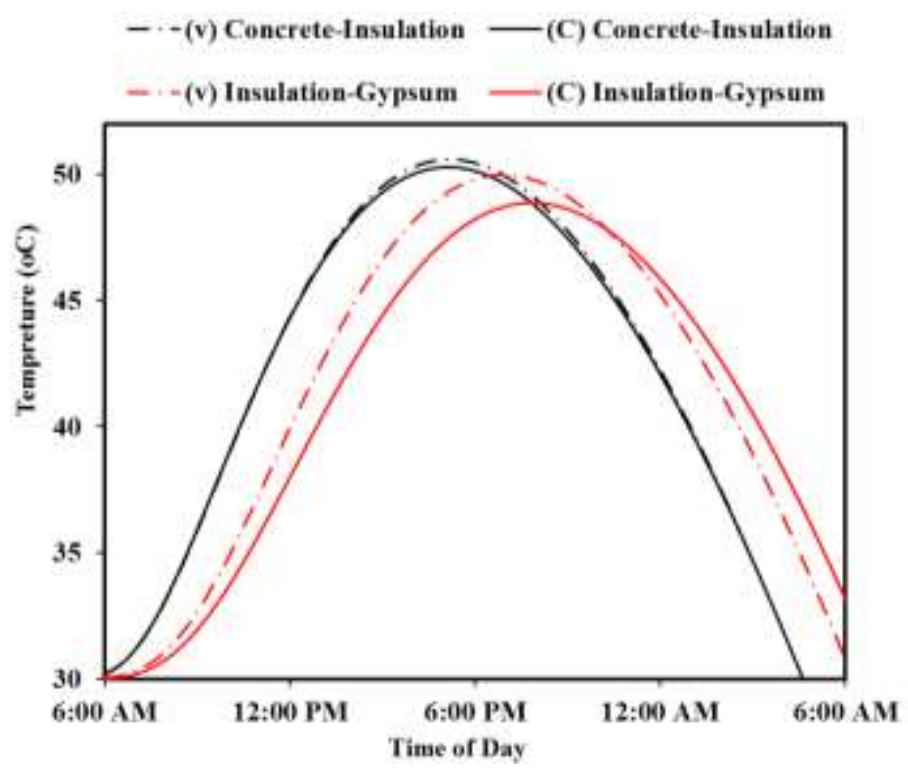

Fig. 2: Temperature profile of the concrete-insulation boundary and insulation-gypsum boundary for catalogue thermal conductivity as a reference (solid lines) and variable thermal conductivity (dashed lines) of dry low-density polystyrene.

\subsection{Density Effect on the Change of the Temperature}

The change of the temperature $(\Delta T)$ between the constant and the variable $\lambda$-value of the EPS at the insulationgypsum layer for the four level of densities is shown by Fig. 3. As the density increases from LD to UHD, $\Delta \mathrm{T}$ decreases due to the high heat transfer for both cases of constant and variable $\lambda$. The peak of $\Delta \mathrm{T}$ with polystyrene $\mathrm{LD}, \mathrm{HD}$ and $\mathrm{UHD}$ are $2,1.7$ and $1.5^{\circ} \mathrm{C}$, respectively. 


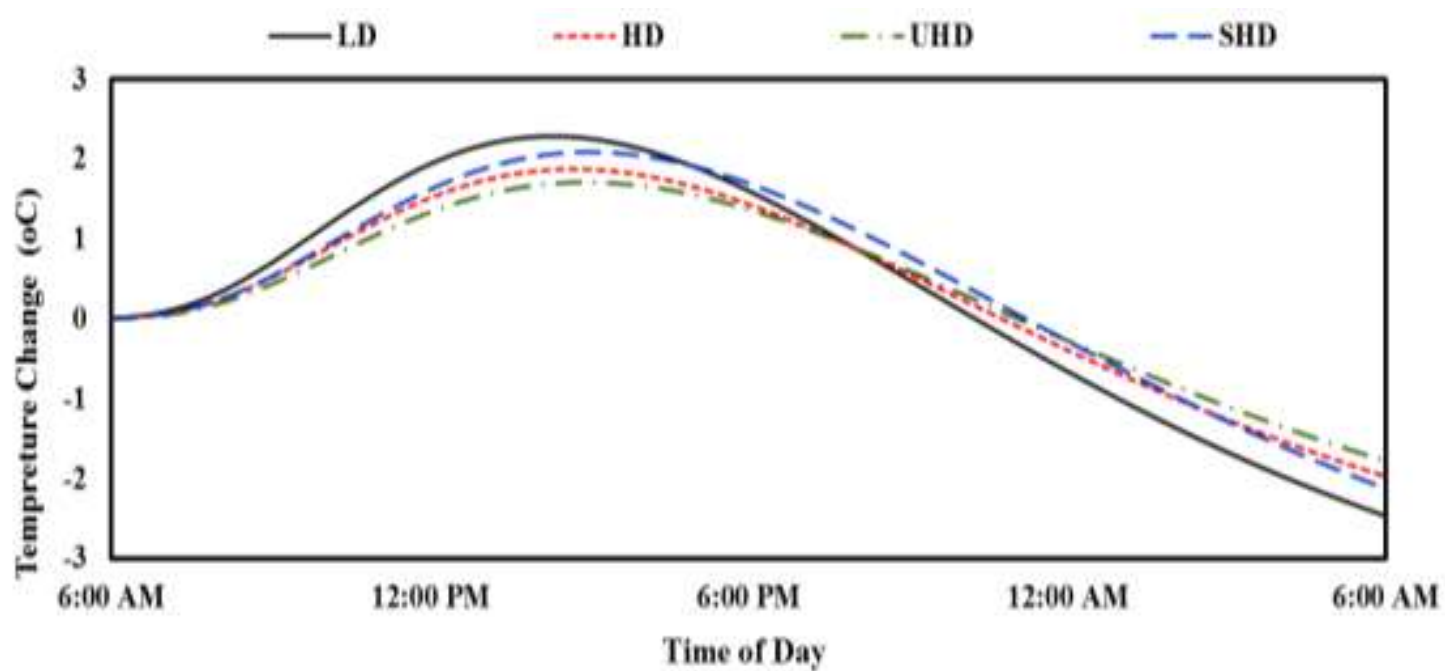

Fig. 3: Daily temperature change $(\Delta \mathrm{T})$ at the insulation-gypsum layer of polystyrene with different density levels: Low (LD), high (HD), Ultra high (UHD), and super high (SHD).

\subsection{Moisture Effect on the Change of the Temperature}

Figure 4 shows the change in temperature $(\Delta \mathrm{T})$ of the thermal conductivity of the insulation at different levels of moisture $(10 \%, 20 \%$ and $30 \%)$. As the moisture content increases, $\Delta \mathrm{T}$ decreases slightly. The peak $\Delta \mathrm{T}$ in case of dry low-density is $2.28{ }^{\circ} \mathrm{C}$, while with the moisture content of $10 \%, 20 \%$ and $30 \%$, the $\Delta \mathrm{T}$ are $2.19,2.08$ and $1.797{ }^{\circ} \mathrm{C}$, respectively.

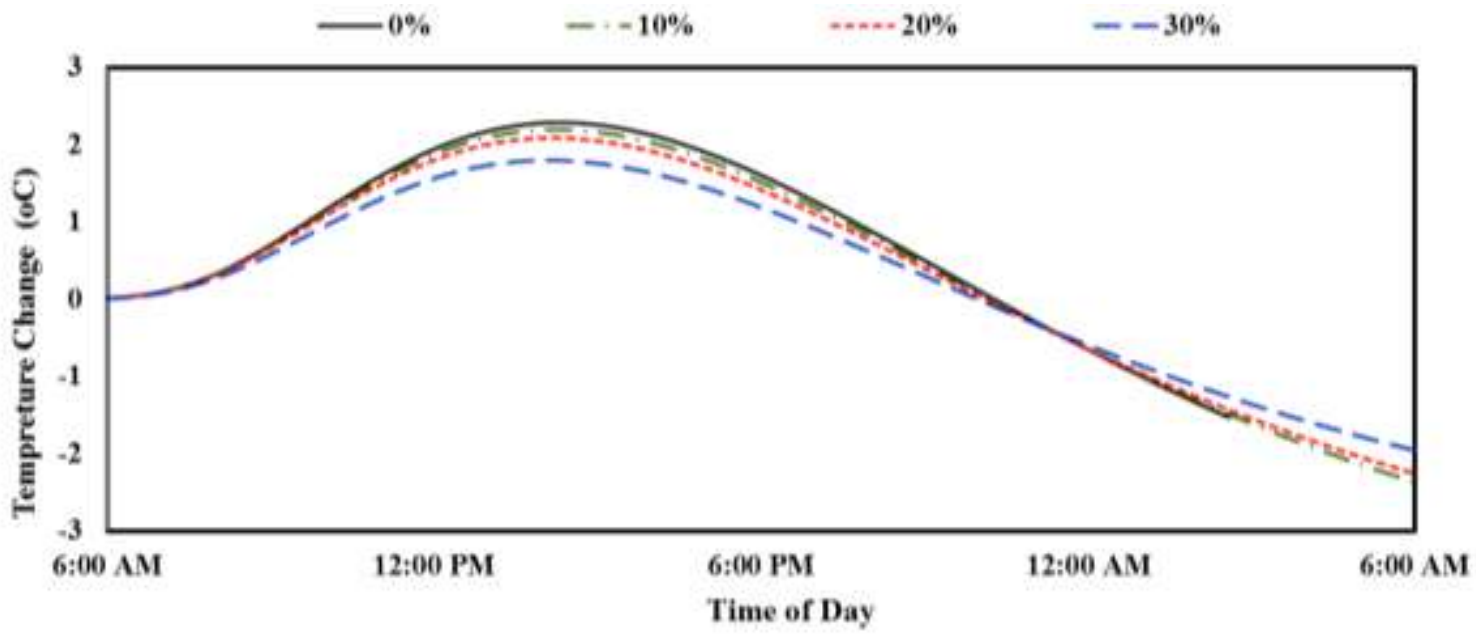

Fig. 4: Daily temperature change $(\Delta \mathrm{T})$ at the insulation-gypsum layer of low-density polystyrene at moisture content of $0 \%$, $10 \%$, $20 \%$, and $30 \%$.

\subsection{Energy Performance in Building}

\subsubsection{Cooling Demand and Cooling Capacity}

The energy demand required for cooling the residential house located in AL-Ain is obtained with constant and variable thermal conductivity of the dry LD polystyrene and the result is shown in Fig. 5. 


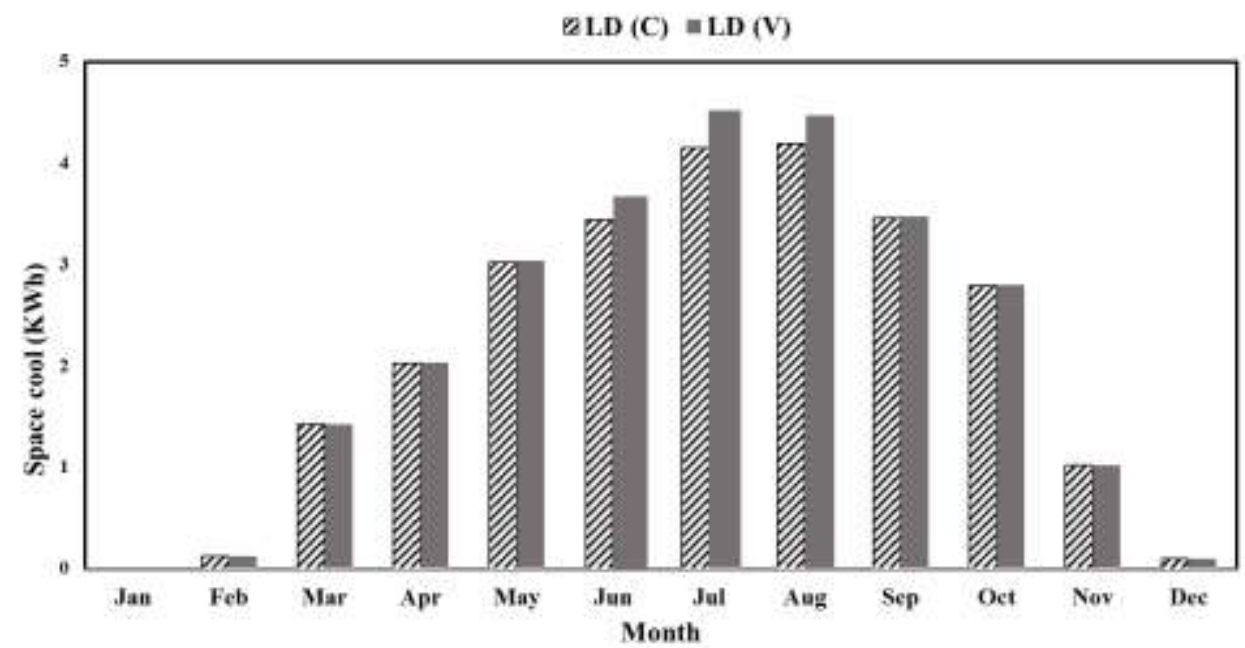

Fig. 5. Required space cooling employing dry low-density polystyrene with constant (dashed bars) and variable (solid bars) thermal conductivity for residential building in hot climate of UAE.

The monthly energy consumption for cooling required by the residential building is not uniformly distributed across the year. Indeed, the energy demand is maximum during the hot months July and August. Thus, the changes in cooling demand between using constant and variant thermal conductivity reached the maximum in these months. The peak cooling demand for polystyrene with constant and variable thermal conductivity are $4.15 \mathrm{KWh}$ and $4.32 \mathrm{KWh}$, respectively

\subsubsection{Cooling Demand and Cooling Capacity}

The yearly average cooling demand and the cooling capacity of the AC system to remove the heat from the space are obtained for different level of polystyrene densities and different levels of moisture content as shown in Fig. 6 and Fig.7, respectively.

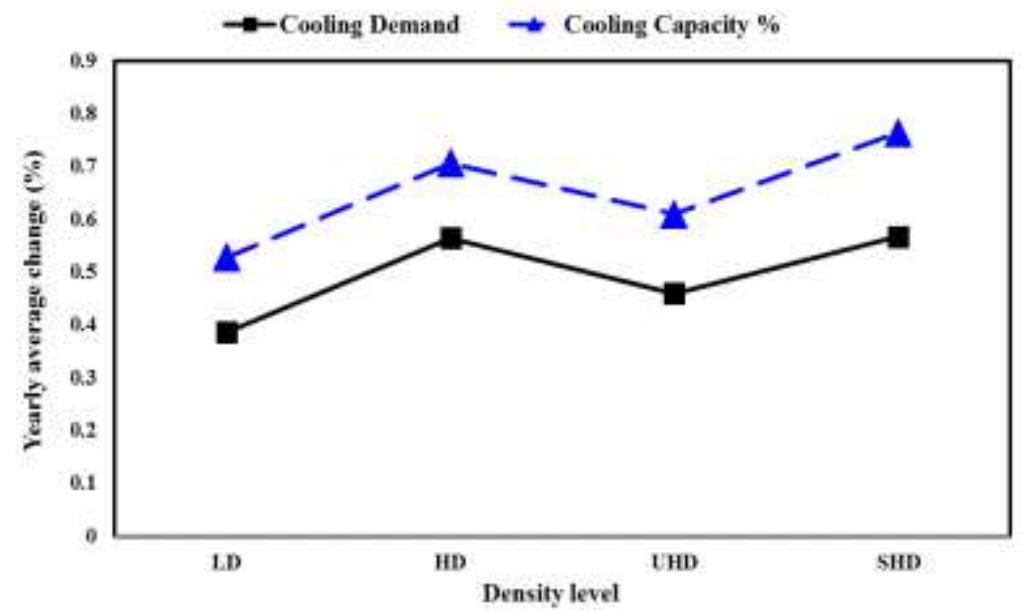

Fig. 6: Yearly average change (\%) in space cooling demand and cooling capacity employing dry polystyrene with constant and variable thermal conductivity at different density levels for residential building in hot climate of UAE.

Among different polystyrene densities, LD results in the lowest yearly average change in cooling demand and capacity with $0.4 \%$ and $0.55 \%$, respectively. SHD shows the highest change in cooling demand and capacity of $0.5 \%$ and $0.7 \%$, respectively.

\subsubsection{Moisture effect on Cooling Demand and Cooling Capacity}

The yearly average change in cooling demand and capacity for polystyrene at different moisture levels is presented in Fig. 7. The change for the dry polystyrene is not significant with less than 1\%. While, as the moisture increase to $10 \%$, 
the yearly average change for cooling demand and capacity increased to $4.8 \%$ and $5 \%$, respectively. Further increment in the change of cooling demand and capacity occurred as the moisture level increases to $20 \%$ of the polystyrene content reaching up to $6 \%$ and $8.2 \%$, respectively. The highest change in cooling demand and capacity were $6.5 \%$ and $8.9 \%$ in case of polystyrene with $30 \%$ moisture content.

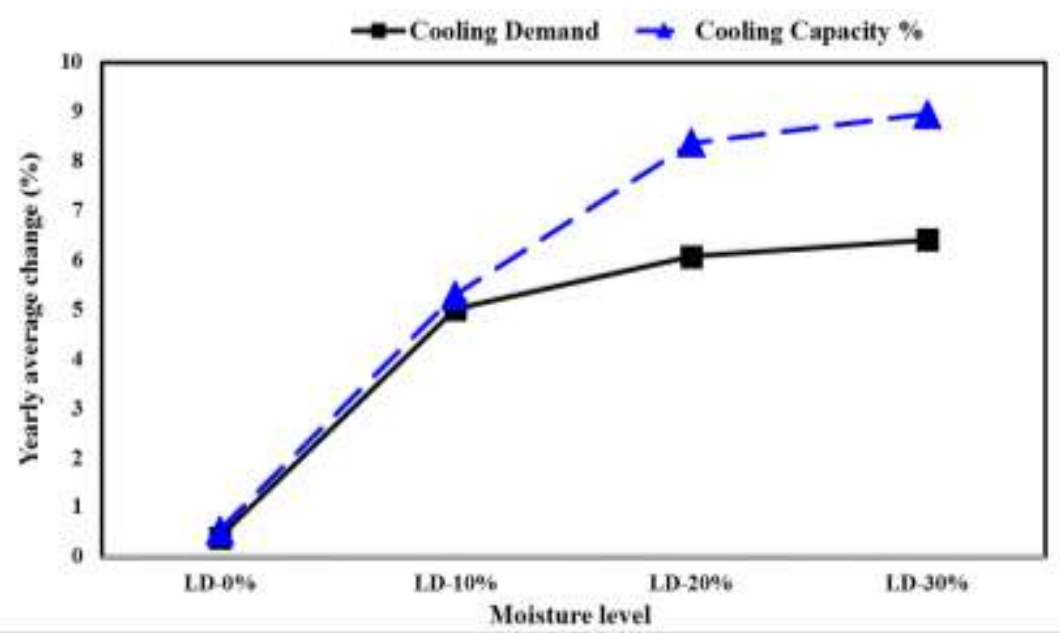

Fig. 7. Yearly average change (\%) in space cooling demand and cooling capacity employing dry polystyrene with constant and variable thermal conductivity at different moisture levels for residential building in hot climate of UAE.

\section{Conclusion}

The work presented in this paper illustrates the impact of variable thermal conductivity values of the insulation layer embedded in a typical wall on the cooling effect and energy performance of buildings in extremely hot climate of UAE. Insulation materials are generally assumed to have a fixed thermal conductivity provided by the suppliers. However, their thermal conductivities exhibit variation with both operating temperature and moisture content. The thermal performance of the building when the insulation layer is assumed to have variable thermal conductivity was compared to that of a nonvariable thermal conductivity by quantifying the additional heat transferred due to the $\lambda$-relationship with the time. The model was used to numerically evaluate insulation material (polystyrene) with four densities denoted as $\mathrm{LD}(12 \mathrm{~kg} / \mathrm{m} 3)$, $\mathrm{HD}(20 \mathrm{~kg} / \mathrm{m} 3), \mathrm{UHD}(30 \mathrm{~kg} / \mathrm{m} 3)$ and SHD $(35 \mathrm{~kg} / \mathrm{m} 3)$, and three moisture content levels $(10 \%, 20 \%$ and $30 \%)$ compared to dry insulation material for $\mathrm{LD}$ material.

During the daytime, using variable $\lambda$ results in a higher temperature rise on the surfaces compared to the reference case based on constant thermal conductivity of the insulation material. As the density increases from LD to UHD, $\Delta \mathrm{T}$ decreases due to the high heat transfer for both cases of constant and variable $\lambda$. The yearly average cooling demand and the cooling capacity of the AC system to remove the heat from the space are obtained for different levels of polystyrene densities and different levels of moisture content. Indeed, among the four densities, the LD results in the lowest yearly average change in cooling demand and capacity. Moreover, the yearly average change in cooling demand and capacity for EPS at various moisture levels is also investigated. Indeed, the sample with $30 \%$ moisture content exhibits the highest change in cooling demand and capacity.

\section{Acknowledgement}

This work is supported by the Research Start-up grant, UAE University (Grant No. G00002665).

\section{References}

[1] Energy Information Administration (EIA), Washington, DC, 2011.

[2] International Energy Agency (EA), Paris, France, 2011.

[3] M. Khoukhi, "The combined effect of heat and moisture transfer dependent thermal conductivity of polystyrene insulation material: impact on building energy performance," Energy Build., vol. 228, pp. 235-169, 2018. 
[4] Energy Performance of Buildings Directive (EPBD), Directive 2010/31/EU of the European Parliament and of the council of 19 May, 2010.

[5] Energy Efficiency Directive (EDD), Directive 2012/27/EU of the European Parliament and the council of 25 October, 2012.

[6] I. Budaiwi, A. Abdou, M. Al-Homoud, "Variation of Thermal Conductivity of Insulation Materials under Different Operating Temperatures: Impact on Envelope-Induced Cooling Load,” J. Arch. Eng., vol. 8, no. 4, pp. 125-132, 2002.

[7] A. Abdou, I. Budaiwi, "Comparison of thermal conductivity measurements of building insulation materials under various operating temperatures," J. Build. Phys. vol. 29, no. 2, pp. 171-184, 2005.

[8] U. Berardi, "A cross-country comparison of the building energy consumptions and their trends," Resour. Conserv. Recycl., vol. 230, pp. 241-123, 2017.

[9] H. William. (2010). Energy conservation in modern office buildings. [Online]. Available: https://doi.org/10.2190/2L53-DUCW-J1B8-MMYW

[10] M. Khoukhi, N. Fezzioui, B. Draoui, L. Salah, "The impact of changes in thermal conductivity of polystyrene insulation material under different operating temperatures on the heat transfer through the building envelope,' Appl. Therm. Eng., vol. 669, pp. 674-105, 2016.

[11] D.F. Aldrich, R.H. Bond, "Thermal performance of rigid cellular foam insulation at subfreezing temperature thermal performance of exterior envelopes of buildings III," in Proceedings of the ASHRAE/DOE/BTECC Conference, Florida, USA, 2-5 December, 1985.

[12] M. Khoukhi, M. Tahat, "Effect of operating temperatures on thermal conductivity of polystyrene insulation material: impact on envelope-induced cooling load," Appl. Mech. Mater., vol. 315, pp. 320-564, 2014.

[13] M. Khoukhi, M. Tahat, "Effect of temperature and density variation on thermal conductivity of polystyrene insulation materials in Oman," J. Eng. Phys. Thermophys, vol. 994, pp. 998-88, 2015.

[14] M.C. Chyu, X. Zeng, L. Ye, "The effect of moisture on the performance of polyurethane insulation used on a district heating and cooling pipe," ASHRAE Trans., vol. 309, pp. 317-103, 1997.

[15] J.N. Reddy, D.K. Gartling, The Finite Element Method in Heat Transfer and Fluid Dynamics. CRC press, 2010.

[16] M.C. Chyu, X. Zeng, L. Ye, "Performance of fibers glass pipe insulation subjected to underground water attack," ASHRAE Trans., vol. 303, pp. 308-103, 1997. 